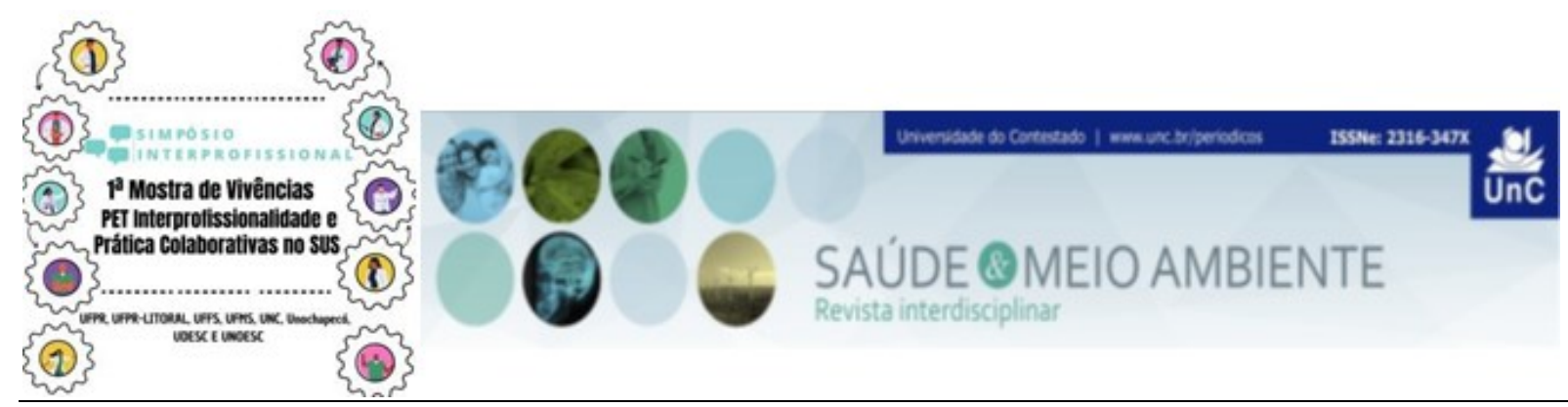

\title{
VIGILÂNCIA EPIDEMIOLÓGICA DOS CASOS E DA INCIDÊNCIA DA DENGUE NO LITORAL PARANAENSE DURANTE PANDEMIA DE COVID-19
}

\author{
PET INTERPROFISSIONALIDADE-Projeto $93^{1}$
}

\author{
Jéssica Fritz da Silva ${ }^{2}$ \\ Tainá Ribas Mélo ${ }^{3}$ \\ Roberto Eduardo Bueno ${ }^{4}$ \\ Evaldo Ribeiro $\mathrm{Jr}^{5}$
}

\begin{abstract}
RESUMO
Introdução. A Dengue é uma doença grave causada por arbovírus da família Flaviviridae, transmitidos por picadas de insetos, especialmente pelos mosquitos Aedes aegypti, que precisa de água parada para sua proliferação. Por isso a importância de manter a higiene e evitar água parada. Pessoas de todas as faixas etárias são igualmente suscetíveis a dengue, contudo os idosos possuem maior risco de desenvolver quadros graves e complicações que podem levar à óbito. No atual contexto da pandemia de COVID-19 torna-se ainda mais urgente a implementação de ações de monitoramento, prevenção e controle, visando que as ações ocorram precocemente à efetividade das estratégias de enfrentamento da disseminação da dengue. Objetivos. Os objetivos desta pesquisa de vigilância epidemiológica da incidência da dengue no litoral paranaense são o monitoramento, prevenção e a publicização de casos novos de dengue para o planejamento de estratégias de redução do número de casos e da ocorrência de surtos no litoral paranaense. Metodologia. Utilizou-se a técnica de monitoramento epidemiológico comparativo das informações sobre o total dos casos confirmados e a incidência de autóctones (por 100.000 habitantes por município) da dengue nos sete municípios do Paraná, publicadas no boletim da Secretaria da Saúde do Estado do Paraná (SESA/PR)[1] referentes à última Semana Epidemiológica disponível de cada mês, de janeiro a julho de 2019 e 2020. Resultados. Diante dos resultados obtidos, evidenciam-se no litoral paranaense um aumento progressivo dos casos de dengue em 2020, maior evidenciado a partir de final de abril, atingindo os totais de casos de dengue

${ }^{1}$ Fonte de financiamento: Programa de Educação pelo Trabalho para a Saúde - PET

Saúde/Interprofissionalidade 2019-2021 (Edital no 10 de 23 de julho de 2018, Ministério da

Saúde/Secretaria de Gestão do Trabalho e da Educação na Saúde)

${ }^{2}$ Bolsista PET Saúde. Estudante do Curso de Bacharel em Saúde Coletiva - Universidade Federal do

Paraná - Setor Litoral. Paraná. Brasil. E-mail: jessicafritzsilva@gmail.com

${ }^{3}$ Tutora PET Saúde. Docente do Curso de Bacharel em Saúde Coletiva - Universidade Federal do

Paraná - Setor Litoral. Paraná. Brasil. E-mail: ribasmelo@ufpr.br

${ }^{4}$ Tutor PET Saúde. Docente do Curso de Bacharel em Saúde Coletiva - Universidade Federal do

Paraná - Setor Litoral. Paraná. Brasil. E-mail: roberto.bueno@ufpr.br

${ }^{5}$ Tutor e coordenador de equipe PET Saúde. Docente do Curso de Licenciatura em Educação Física Universidade Federal do Paraná - Setor Litoral. Paraná. Brasil. E-mail: evaldo.ribeiroir@ufpr.br
\end{abstract}


confirmados; e a incidência de autóctones, respectivamente: Paranaguá: 1.706;1.093,93; Guaratuba: 93; 248.67; Pontal do Paraná: 88; 304,10; Matinhos: 71; 143,25; Morretes: 35; 171,09; Antonina: 1; 5,26; Guaraqueçaba: 1; 0,00, valores muito superiores aos que foram encontrados nos mesmos períodos em 2019.Conclusão. É imprescindível ações de vigilância e promoção da saúde ambiental, principalmente nesta época em que estamos passando, onde há um aumento progressivo de casos de dengue no litoral paranaense ao qual gera um alerta considerando que se soma ao cenário da pandemia de COVID-19, a prevenção e controle da dengue nos municípios do litoral paranaense para a mitigação e possível erradicação do mosquito Aedes aegypti, vetor e transmissor dos vírus de doenças como a dengue, zika e chikungunya, em todo o território epidêmico investigado.

Palavras-chaves: Monitoramento Epidemiológico. Aedes aegypti. Vigilância em Saúde Pública.

\section{REFERÊNCIAS}

[1] Secretaria da Saúde (SESA/PR). Boletim da Dengue - Combate à Dengue [acesso em 19 de julho de 2020] Disponível em http://www.dengue.pr.gov.br/ modules/conteudo/conteudo.php?conteudo $=28$ 